\title{
Solidaridad familiar, emprendimiento y fórmulas de supervivencia económica de los primeros colonizadores españoles en el Nuevo Reino de Granada, 1540-1604
}

\author{
Family Solidarity, Entrepreneurship and Economic Survival Alternatives \\ of the First Spanish Settlers in the New Kingdom of Granada, 1540-1604
}

\begin{abstract}
Roger Pita Pico
Politólogo de la Universidad de los Andes (Bogotá) y magíster en Estudios Políticos de la Pontificia Universidad Javeriana. Director de la Biblioteca "Eduardo Santos" de la Academia Colombiana de Historia, Bogotá D. C. - Colombia hhttp://orcid.org/0000-0001-9937-0228

rogpitc@hotmail.com

Fecha de recepción: 18 de abril de 2017

Fecha de aceptación: 17 de julio de 2017
\end{abstract}

Sugerencia de citación: Pita Pico, R. (2017). Solidaridad familiar, emprendimiento y fórmulas de supervivencia económica de los primeros colonizadores españoles en el

Nuevo Reino de Granada, 1540-1604. tiempo\&economía, 4(2), 9-29, doi: http://dx.doi.org/10.21789/24222704.1220

\section{RESUMEN}

Con base en las cartas privadas recopiladas por Enrique Otte, el propósito de este artículo consiste en examinar en detalle las fórmulas de supervivencia, el emprendimiento económico y la solidaridad familiar de los primeros colonizadores españoles con miras a alcanzar el progreso y la estabilidad en el territorio del Nuevo Reino de Granada durante la segunda mitad 
del siglo XVI. El trabajo corrobora las buenas perspectivas que ofrecían los dominios americanos en contraste con la difícil situación que se vivía en España y pone de presente la estrategia del casamiento como fórmula de impulso económico en las nuevas tierras por explorar. En cierto modo, estos pobladores pioneros vencieron temores y abrieron el camino para las posteriores olas masivas de emigrantes españoles. Fueron ellos los que sentaron las bases de proyectos económicos dejando como legado valiosas experiencias y alternativas de adaptación social.

Palabras clave: historia económica, migración, colonización, emprendimiento, Colombia Códigos JEL: N36, F22, F24, J61, L26

\begin{abstract}
Based on Enrique Otte's collection of private letters, the purpose of this article is to examine in detail the alternatives for survival, economic entrepreneurship and family solidarity of the first Spanish settlers with a view to achieving progress and stability in the territory of the New Kingdom of Granada during the second half of the sixteenth century. The work corroborates the good prospects offered by the American domains in contrast to the difficult situation in Spain and emphasizes the strategy of marriage as a formula of economic momentum in the new land to be explored. In a way, these pioneer settlers overcame fears and paved the way for the subsequent massive waves of Spanish emigrants. They were the ones who laid the foundations of economic projects leaving valuable legacies experiences and alternatives of social adaptation.
\end{abstract}

Keywords: Economic history, migration, colonization, entrepreneurship, Colombia

JEL Codes: N36, F22, F24, J61, L26 


\section{Introducción}

La evolución de la economía colonial hispánica desde la segunda mitad del siglo XVI estuvo orientada hacia el sistema mercantilista en una fase crucial de transición entre el feudalismo y la era del capitalismo (Colmenares, 1998, p. 9). El objetivo primordial era incrementar las riquezas del vasto imperio. Esto implicaba, desde luego, explotar las abundantes riquezas, concentrándose los esfuerzos extractivos en la promisoria producción minera.

En las Ordenanzas promulgadas en 1573 por el rey Felipe II, se planteó la necesidad de limitar el uso de la fuerza y la espada impuesta en las primeras jornadas de Conquista y dominación sobre las comunidades indígenas para dar paso al impulso del proceso de fundación de ciudades, para lo cual era clave el auge de la colonización con la llegada masiva de españoles dispuestos a sentar las bases del desarrollo social y económico en estos territorios novohispanos (Ramos, 1947, p. 274). Así entonces, a la par de esta dinámica colonizadora, el Estado español buscó extender su aparato institucional y su sistema fiscal y de gobierno (Pérez, 1992, pp. 73-75).

La primera avanzada de esta colonización se limitó a tierras que habían estado ocupadas por los indígenas, pues estas áreas eran las que podían ofrecer mejores alternativas de supervivencia ante la escasa capacidad económica de aquellos primeros pobladores blancos. Las zonas vírgenes resultaban aún inaccesibles (Friede, 1965, Vol. II, pp. 71-126).

En este contexto, el propósito de este artículo consiste en examinar en detalle las fórmulas de supervivencia, el emprendimiento económico y la solidaridad familiar de estos pioneros pobladores españoles con miras a alcanzar el progreso y estabilidad en el territorio del Nuevo Reino de Granada durante la segunda mitad del siglo XVI.

Este trabajo, inscrito temáticamente dentro del marco de la historia económica', se realizó con base en la recopilación realizada por el historiador español Enrique Otte bajo el título Cartas privadas de emigrantes a Indias 1540-1616 (1996, pp. 280-362). Estas cartas fueron incluidas en los expedientes de solicitud de licencias de emigrados a Indias, tramitados por los primeros pobladores españoles residentes en este lado del Atlántico².

El género epistolar ha adquirido especial auge en las últimas décadas como un importante filón historiográfico y prueba de ello fue, precisamente, este acervo de cartas. Si bien sobre esta época existían otros epistolarios, la mayoría de ellos correspondía a documentos de carácter oficial, alusivos a asuntos políticos o negocios públicos (Martínez, 1992, pp. 7-8).

Así entonces, la virtud de la obra de Otte es haber abierto una compuerta hacia el estudio de la vida privada y la mentalidad de los colonizadores españoles en momentos en que aún se realizaban campañas de conquista ${ }^{3}$ y exploración del nuevo territorio.

1 La mayoría de trabajos historiográficos sobre económica colonial en Colombia se han concentrado en los siglos XVII, XVIII y principios del XIX. Por ello, la apuesta de este artículo consiste en aportar más luces sobre los primeros años de dominio hispánico, época en la cual las fuentes de información y los análisis son mucho más escasos.

2 De un total de 650 cartas transcritas por Otte, para el caso específico de este artículo se seleccionó una muestra de 82 comunicaciones remitidas desde ciudades, villas y parajes del Nuevo Reino de Granada.

3 Como antecedente, vale precisar que el historiador José Ignacio Avellaneda Navas (1995) realizó un riguroso tiempo\&economía Vol. 4 N. ${ }^{\circ} 2$ - Julio - Diciembre de 2017 
La economía ocupa un lugar preponderante en el contenido de estas cartas y es a partir de allí que se intenta abordar el análisis bajo las siguientes temáticas: la ayuda económica a los familiares residentes en España, el llamado a familiares para impulsar la economía del Nuevo Reino, las alternativas de emprendimiento económico aplicadas en estas tierras, el contraste de experiencias exitosas y malogradas a uno y otro lado del océano Atlántico y, por último, el estudio del casamiento como fórmula planificada de progreso económico.

\section{La ayuda económica a familiares en España}

Es importante partir del hecho histórico de que la América hispánica fue poblada más que todo por solteros blancos y no por familias enteras como en los dominios ingleses (Mörner, 1969, p. 27).

La decisión de movilizarse hacia tierras del Nuevo Mundo era en principio una aventura individual que implicaba afrontar, como primer reto económico, la consecución de recursos para sufragar el alto costo que significaba embarcarse en tal travesía transatlántica ${ }^{4}$. Los aventureros mantenían viva la esperanza de trasladar en un futuro cercano a sus familiares para implantar allí proyectos productivos.

Así entonces, viajar a América implicaba muchas veces dejar a los padres y hermanos a la deriva con la incertidumbre de no poder enviar ayuda económica hasta tanto no lograra radicarse y producir en las nuevas tierras. En ese sentido, en un principio pudo operar muy bien la solidaridad de los familiares que vivían al interior de España para solventar las necesidades básicas mientras empezaban a llegar los giros de América. Este tipo de apoyo era, en cierta manera, una muestra de la prosperidad que se palpaba en las tierras por colonizar.

Diego de Saldaña se declaró en 1590 muy agradecido con los hermanos y tíos de su mujer que le habían ayudado en España a apaciguar sus necesidades durante su ausencia. Este aventurero estaba a la espera de enviar algún dinero en la próxima flota. De igual modo, tuvo el cuidado de recomendarle a su esposa que a su venida no dudara en regalarles a aquellos benefactores algunas de sus pertenencias en retribución por el incondicional apoyo recibido (Otte, 1996, p. 307).

A través de varias cartas, Clara de los Ángeles, residente en la ciudad de Toledo en España, le había pedido encarecidamente a su marido aventurero Baltasar de Valladolid que no se olvidara de ella ni de sus hijos y que hiciera todo lo posible para enviar dinero, pues hacía ya algún tiempo estaba bajo el amparo de su casa paterna. A estos reclamos, Baltasar le recordó que había llegado pobre a América y estaba haciendo el mayor esfuerzo para conseguir al menos con qué mantenerse, porque según dijo "las Indias no son para los que vienen pobres, que el que no trae no lleva, y esto ten por verdad" (Otte, 1996, p. 284).

estudio sobre la situación social y económica de los integrantes de las huestes de Conquista al mando de los más destacados expedicionarios que incursionaron en el territorio del Nuevo Reino de Granada. De hecho, algunos de los remitentes o de sus ascendientes incluidos en la recopilación epistolar de Otte se pueden rastrear en aquellos perfiles genealógicos elaborados por Avellaneda Navas.

4 En ciertos momentos, la Corona debió intervenir para que los dueños de navíos ofrecieran precios justos y moderados. No obstante, el viajero tenía la opción de diferir el pago del pasaje (Rodríguez, 2017, pp. 1504-1511). 
Tal como se puede advertir en las cartas en que se anunciaban el envío de remesas, el principal propósito era el sustento básico de los deudos. Desde la ciudad de Tocaima, Antonio Portillo Cantalejo remitió a la península ibérica 50 pesos: 30 para su hermana y 20 para su tío Francisco Basto.

Los pobladores españoles en América también enviaron auxilios para otro tipo de prioridades terrenales y espirituales. Juan de Ezpeleta, domiciliado en Cartagena, giró en 1573 un total de 85 pesos de oro para su sobrino Juan Jiménez de Oco con miras al financiamiento de sus estudios en uno de los colegios de Madrid. Por su parte, Francisco González de Castro remitió a sus parientes residentes en la ciudad de Trujillo un "pedazo" de oro de 23 quilates para el casamiento de una de sus familiares más cercanas.

Catalina Ruiz de Avilés, residente en España, recibió en 1571 instrucciones de su esposo Alonso Rodríguez, radicado en la población de Cáceres en la provincia de Antioquia, para que del oro que recibiría con la carta, le entregara a los religiosos de la comunidad de Nuestra Señora del Monte Carmelo, residentes en La Paz, un total de 150 reales para que cada viernes durante un año se oficiase en su nombre una misa rezada y 100 reales adicionales de limosna "con cargo que cada sábado digan una salve cantada con el órgano y su responso cantado" (Otte, 1996, p. 321). Rodríguez mantenía su ilusión en que la inversión hecha en estos rezos se viera después resarcida con mayor prosperidad económica por cuenta de la protección divina en sus andanzas en América y con la esperanza de regresar a ver sus seres queridos.

En esta modalidad de cooperación filial, vale precisar que la economía para los exploradores pioneros en territorio americano no fue siempre próspera y estable, circunstancia que pudo dilatar aún más las posibilidades de socorrer oportunamente a los parientes ubicados al otro lado del Atlántico. Desde Popayán, Alonso Rodríguez escribía a su hermano en un tono desilusionado tras no poder enviarle algún dinero sino hasta cuando se asomara la próxima flota.

El tesorero de aquella misma ciudad ubicada al sur del Nuevo Reino también se sintió desconcertado por no haber remitido dinero a comienzos de 1578 a sus dos hermanos residentes en La Mota, pues al momento en que escribía la carta apenas se estaba fundiendo una plata hallada en tres minas que agenciaba en inmediaciones de la población de San Sebastián, laboreo que hubiera sido más productivo si no fuera por el ataque de los indios belicosos que hacía poco habían incinerado el pueblo.

En una de sus comunicaciones escritas desde la ciudad de Muzo, el colono Alonso Ramírez Gasco confesó que no había podido enviar dinero a sus deudos por haber afrontado cinco años de enfermedad "muy trabajosa y costosa". Pero, una vez superado este impasse, estaría presto a enviarles algún capital con el cual pudieran aliviar sus penurias económicas.

Una situación similar a esta le ocurrió a Alonso de Valderrama, quien en 1580 se lamentaba de no haberle podido remitir algún tejuelo de oro a su padre para remediarle algunas de sus precariedades. Durante cinco meses permaneció inhábil para trabajar en la provincia de Cartagena por estar cojo y por causa de una calentura a la que debió gastarle 150 ducados que, por cierto, debió pedir prestados. Él esperaba que con suerte podía quizás en la próxima flota enviarle algo a sus seres queridos.

La imposibilidad de mandar ayuda económica a España no siempre fue comprendida por los familiares, que en ocasiones optaban por una postura de desconfianza, indiferencia u olvido.

tiempo\&economía

Vol. 4 N. ${ }^{\circ} 2$ - Julio - Diciembre de 2017 
Esta fue la explicación que dio Baltasar de Valladolid, asentado en Santa Fe, ante los reclamos y dudas de su esposa sobre la verdadera voluntad de aquel hombre para salir adelante económicamente: "podrás entender que de entrambos vicios [las mujeres y el juego] estoy bien apartado, porque más cuidado tengo en cómo tengo de ganar de comer para volver a verte a ti y a tus hijos y a todos mis amigos y parientes. Y esto ruego a Dios muy encarecidamente cada día" (Otte, 1996, p. 284).

En 1581 Luis de Larraga, residente en el puerto de Cartagena, sospechaba que el prolongado silencio de su mujer se debía a su "mala suerte" económica por la cual no se merecía ni siquiera una nota de afecto. En una carta escrita el año anterior desde la ciudad de Tunja, Bartolomé de Moya lamentó el olvido de su hija y la calificó de interesada, pues únicamente respondía cartas cuando él enviaba algún dinero. Por ello, le pedía no ser "desagradecida" con el mucho amor que a ella le profesaba.

\section{Los Ilamados y el acrecentamiento del patrimonio familiar}

La mayoría de cartas de los colonizadores españoles tenía una solicitud en particular: intentar por todos los medios que sus familiares y amigos vinieran a América para ayudar a forjar fortunas, dadas las buenas perspectivas que se vislumbraban en estas tierras novohispanas.

Si bien se contaba con una apreciable cantidad de mano de obra indígena y de algunos negros esclavos, la realidad es que sobre estos grupos étnicos primó una percepción despectiva y negativa, pues recurrentemente se hacía referencia a ellos como vagos, perezosos, ladrones y de inficionadas costumbres (Pita, 2015, p. 424). Es por esto que aquellos primeros emigrantes españoles estaban esperanzados en que personas de su misma sangre u otras cercanas de confianza pudieran colaborarles en el manejo económico y que, a la vez, fueran una compañía valiosa en la soledad del anchuroso suelo americano.

Algunos que ya llevaban varios años batallando en estas tierras buscaron un relevo con algún familiar. Cristóbal de Vivas, residente en la villa de San Cristóbal en la frontera con Venezuela, estaba a la expectativa de que su hijo viniera para que se encargara de su casa y de sus haciendas y poder él "dar una vuelta por allá [en España], pues tanto lo deseo" (Otte, 1996, p. 317).

Sin embargo, problemas en el estado físico y en la salud, así como también las ocupaciones económicas contraídas en América, eran factores que impedían a muchos colonizadores españoles regresar a su patria chica, ante lo cual centraban todo su esmero en buscar la forma de que sus seres queridos cruzaran el océano Atlántico. No hay que perder de vista el hecho de que la posibilidad real de viajar a España con el único fin de traerlos podía resultar bastante costosa y dispendiosa.

Alonso Herojo se hallaba viejo y cojo, razones que le impedían emprender viaje a España. Diego Morales expresó a su mujer e hijos, residentes en las Palmas de Gran Canaria, que vinieran lo más pronto posible. Su intención hubiese sido irlos a buscar, pero sus compromisos económicos se lo impedían. Jiménez de Cuadrado también expresó su imposibilidad de ir a España, ya que había invertido todo su caudal en la adquisición de una casa y en unas labranzas que no podía dejar abandonadas, siendo además muy difícil venderlas pues no recibiría el precio justo por estos activos. Alonso de Trujillo, residente en Cartagena, reconoció su difi- 
cultad de regresar a España por estar empeñado en la compra de una huerta y otros cultivos. El mercader Hernando López Calcinas, radicado en este mismo puerto caribeño, veía también remota la esperanza de comprar su pase de retorno por haber fiado ropa que compró a largo plazo para comercializarla.

Sebastián de Llerena persuadió insistentemente a su mujer sobre lo inconveniente que resultaba regresarse por la falta de oportunidades laborales en España y las desbordadas deudas que allí había dejado mientras que en América había encontrado la forma de ganarse la vida siendo su objetivo quedarse al menos tres años más.

Más allá de los sentimientos, los colonizadores españoles debían ponderar muy bien la forma de proveer a sus seres queridos una vida digna en tierras americanas. Marcos Martín le pidió encarecidamente a su mujer que cruzara el Atlántico pues no tenía cómo regresar a Castilla y a él le resultaba más rentable sostenerla aquí porque, si seguía enviándole remesas, viviría pobre toda su vida. En cambio, si ella resolvía venir, había por lo menos el chance de ayudarse mutuamente y de esta forma se avivaba la ilusión de regresar a España "con honra".

Aquellos emigrantes que habían logrado posicionarse económicamente no dudaron en hacer vehementes llamados a sus familiares más cercanos para que vinieran a disfrutar y acrecentar esas riquezas.

Juan de Camargo había logrado acumular en sus diez años de residencia en Tamalameque un cuantioso capital que se acercaba a los 20.000 pesos representados, entre otras cosas, en tres pueblos de indios que rentaban cada uno mil pesos anuales. Justificado en esta bonanza económica, pidió a sus parientes que le enviaran todos sus hijos que habían quedado en España porque podía ya mantenerlos cómodamente.

En jurisdicción de la ciudad de Pamplona moraba un hijo de Cristóbal de Vivas habiendo logrado atesorar un capital de más de 20.000 ducados gracias a las rentas producidas por unas minas de oro explotadas con la fuerza laboral de 30 indios lavadores. Este patrimonio amasado en las nuevas tierras era para él suficiente incentivo para que su hermano residente en España se viniera a estas tierras a trabajar en los negocios familiares.

El sacerdote Francisco Suárez Perea escribió a su hermano relatándole cómo su tío, el capitán Alonso Suárez, había logrado acumular un elevado capital. El cura había sido favorecido de esos dineros pues recibió 15.000 pesos para ordenarse como sacerdote y por ello urgía a su hermano para que no dejara de embarcarse en la próxima flota "pues no será justo que, deseando ellos haceros bien y enviándoos a llamar por esta carta, que la podéis tener por de ambos, que vos no os dispongáis a venir a gozar de la buena coyuntura que se os ofrece" (Otte, 1996, p. 359).

A veces hubo necesidad de hacer una intensa campaña de persuasión para convencer a la familia asentada en España. A Teresa González, domiciliada en la población de Reina, su esposo le comentaba en una carta fechada en marzo de 1583 que viera cómo muchos hombres casados habían probado suerte en las Indias dejando a sus seres queridos y sin tener en las nuevas tierras a ningún amigo, solo motivados por la esperanza de ser guiados por Dios. Por ello, la invitó a no vacilar más y a preparar el viaje pues aquí hallaría "la mesa puesta, y la cama hecha, y la puerta abierta" (Otte, 1996, p. 325). 
A través de una carta suscrita en 1575, la viuda María Bazán de Espeleta quiso animar a su pariente doña Leonor de venir a América por ser la tierra cercana a Tamalameque muy parecida a su sitio de origen, Jerez de la Frontera.

Sin duda, uno de los llamados más sentidos eran los que hacían los colonizadores a sus esposas teniendo como intención recomponer la unión marital y labrar un mejor futuro en América. Este objetivo se enmarcaba dentro del reiterado llamado que hacía la Corona y la Iglesia para propender por la unidad familiar y evitar de paso la "imprudencia" de mezclarse con razas nativas en desmedro de la pureza de sangre.

La idea de traer la esposa entrañaba también un propósito estratégico: procurar que aquellos primeros aventureros no regresaran definitivamente a España, ya que convenía mantenerlos en América para que ayudaran a impulsar el poblamiento y el desarrollo socioeconómico, además de preservar la seguridad en las zonas ya conquistadas (Borges, 1972, pp. 392-393).

Pero para que estas mujeres pudieran emprender sus viajes debían dejar previamente arreglados todos sus asuntos económicos en España, lo cual incluyó la venta de casas y demás activos para tener cómo invertir sólidamente en las nuevas tierras por colonizar.

Isabel López, residente en el puerto de Sevilla, recibió en 1575 una carta de su esposo Diego Daza desde la ciudad de Cartagena con instrucciones muy precisas para embarcarse a América. Antes de partir, Isabel debía arrendar las casas porque la intención era regresar algún día a España para morir en su propia patria. Su marido le sugirió además comprar dos esclavas para el servicio y traer dos camas, almohadas y ropa de lienzo.

Miguel Hidalgo había buscado suerte en América dejando a su esposa María en Villanueva de Alcardete. En 1587 escribió desde Cartagena a su suegro Juan Martínez para que viniera junto con María, pues creía que esta era la mejor tierra del mundo y que no ofrecía mayores peligros.

Cuando había dilaciones, los desesperados maridos recurrieron a una actitud más severa sustentada en la tradición de los principios patriarcales. Alonso Herojo, asentado en la ciudad de Tunja, no suplicó, sino que dio la orden a su mujer Teresa González y a sus hijos de venir a América, según él, afincado "en el poder que tienen los hombres sobre sus mujeres e hijos" (Otte, 1996, p. 325). Herojo se sintió desilusionado al haber enviado a su esposa 200 pesos para que viajara a América, pero ella ni se embarcó ni tampoco había escrito. Redactando la carta "con lágrimas en los ojos", este hombre le pidió a su mujer que le avisara de una vez por todas su decisión: "si no queréis venir, escríbemelo por lo claro, y decíd que no queréis" (Otte, 1996, p. 327). De mantenerse reacia, la culparía a ella de no ofrecerles un mejor futuro económico a sus vástagos en este lado del Atlántico.

Dadas las difíciles condiciones económicas en los inicios del poblamiento español, era clave contar con la solidaridad familiar y los hermanos figuraron preferencialmente en la lista de los Ilamamientos. Francisco Sánchez de Migolla intentó convencer en 1578 a sus dos hermanos para que vinieran a trabajar en las minas de San Sebastián de la Plata, pero también era consciente de la pena que podía acarrearle este nuevo desprendimiento a su madre, pues harto había sufrido ella con la venida de él a América. 
Con estas justificaciones prospectivas, Juan de Mena propuso en 1575 a su hermano Diego que viniera a Cartagena "porque estando juntos nos favoreceríamos el uno al otro, y os valdría a vos más un año que allí veinte" (Otte, 1996, p. 290).

Juan de Tineo trató de convencer a su hermano Alonso para que viniera al Nuevo Reino a unirse a él en las labores de conquista y pacificación de indios, para lo cual creía que podía dedicar bien su tiempo en su condición de "caballero hijosdalgo", lleno de juventud y valentía que lo hacía útil para "servir a Dios y a su majestad el rey don Felipe". Otra carta envió a su padre para que colaborara en la tarea de persuasión. Juan reconoció haber tenido éxito en los seis años que llevaba de labores en estas tierras.

Honda preocupación sentida por aquellas parejas residentes en América que por cualquier circunstancia se quedaban sin hijos, caso en el cual buscaban llenar ese vacío con algún familiar cercano venido de España que, además de brindar afecto, estuviera dispuesto a hacerse cargo del patrimonio heredado. En el fondo de esta clase de tramas existía el temor de que los bienes pasaran a manos de la Corona.

Motivado por una inquietud de esta índole, Juan de Aguilar escribió en 1557 desde el puerto de Cartagena a su cuñado Lope de Parada, aceptándole la propuesta que este le hiciera de enviarle a su hijo Luis. Aguilar era ya un hombre de edad avanzada y temía mucho que su esposa quedara sola en estas tierras americanas sin una compañía y más por el hecho de que "los amigos en estas partes no son fijos". Al joven pariente le había preparado un plan de vida, pues le tenía asegurada una estabilidad económica dejándole todos sus bienes representados en once pueblos de indios, vacas, puercos, caballos, esclavos, plata y enseres de casa.

Magdalena de Castillo enviudó en la ciudad de Santa Fe sin haber procreado hijos. Llena de zozobra por no saber quién legaría su corto capital, envió en 1591 una carta a su sobrina Luisa, domiciliada en Madrid, para que viniera junto con una criada en la primera flota que partiera para América con el fin de encontrar un buen marido y labrarse un mejor futuro. Magdalena prometió contactar al mercader Hernando Rodrigo de Pereira para que le entregase 200 ducados para los gastos del periplo.

En una carta rubricada en 1565, Catalina Álvarez compartió su alegría con su hermano García Martín por haberse comprometido maritalmente en la ciudad de Mariquita con el acaudalado Antón de Palma, un conquistador y poblador de esas provincias, quien tenía a su cargo tres pueblos de indios, sintiéndose ella "señora de vasallos" y la mejor casada de esas tierras. Con sumo dolor y resignación divina, ella reconocía no haber engendrado hijos con Palma, ante lo cual encargó a su hermano que buscase al hijo de su primer matrimonio, de quien había perdido el rastro. El propósito era que este joven se hiciese cargo de la voluminosa herencia.

Antonio Martín llevaba catorce años viviendo en el Nuevo Reino y se sentía ya viejo y agotado a sus 58 años. Su mujer María había fallecido y no tenía otro familiar con quien contar en estas tierras. Esta situación lo animó a rogarle a su sobrino Pedro, residente en la localidad española de La Zarza, que viniese con su esposa e hijos para él "poder vivir descansado" de sus trajines diarios de supervivencia.

Al morir los emigrantes en tierras americanas, aumentó la desazón de sus deudos por no perder los caudales que con tanto tesón habían conseguido. Juan Martín había fallecido en la

tiempo\&economía 
población de Anserma dejando como únicas herederas a sus dos hijas de seis y tres años. Su postrera voluntad era legarles a estas pequeñas 500 pesos y que además fueran trasladadas a España. No obstante, antes de que este designio se cumpliera intervinieron las autoridades locales y traspasaron todos los bienes a nombre de la Corona bajo el argumento de que él no tenía herederos forzosos y que era imprescindible saber si su madre aún vivía en España. El albacea era su compadre Diego Alonso Cid, quien entabló contactos con miras a que le enviaran desde la metrópoli las respectivas probanzas con tres testimonios que debían ser refrendados por escribanos de tres pueblos diferentes. Se pidió despachar urgentemente estos documentos en la primera flota disponible antes de que se dictara sentencia definitiva.

Andrés de León perdió su vida en una de las campañas de pacificación de los indios. Al enterarse de esta calamidad, su primo Mateo adelantó gestiones desde la ciudad de Santa Fe para hacer cumplir la carta testamentaria que este hombre había formalizado dejándole su capital de dos mil ducados a su madre residente en Guadalcanal. Mateo le solicitó encarecidamente a esta mujer que enviara las probanzas certificadas por escribano en las que quedara constancia del vínculo filial ante la amenaza de que esos recursos terminaran en el erario real.

\section{El emprendimiento económico}

Los sectores populares de España se habían percatado, a lo largo del siglo XVI, de cómo la nobleza se enriquecía con muy poco esfuerzo mientras que a ellos no les quedaba más remedio que soportar extenuantes faenas de trabajo para tener cómo subsistir. Así las cosas, el territorio americano se vislumbraba como una opción salvadora para salir del ostracismo económico (Vicens, 1972, p. 310).

Esta ola de colonizadores estaba ya permeada por los ideales de libertad pregonados por el naciente espíritu de modernidad que abogaba por alcanzar la independencia social y económica, en contraposición al tradicional pensamiento feudalista y estamental que ubicaba al vasallo en términos de dependencia y subordinación (Gutiérrez, 1983, pp. 14-15).

Distintas fueron las actividades económicas adelantadas por los primeros colonizadores. Dentro de la extensa lista figuraron labradores, ganaderos, mineros, comerciantes, artesanos ${ }^{5}$ y encomenderos al mando de repartimientos indígenas. Otros se alistaron como militares en las campañas de pacificación de indios, mientras que algunos cumplieron labores de evangelización o desempeñaron cargos oficiales en la incipiente estructura burocrática ${ }^{6}$.

Quizás el mayor sueño de los emigrantes era cómo alcanzar el éxito económico sin que esto implicara abandonar principios, tan en boga en esa época, como la virtud ${ }^{7}$. Alonso Rodríguez estaba muy entusiasmado de que su hermano emprendiera el viaje transatlántico en procura

5 Dentro del gremio de artesanos podemos mencionar: albañiles, pintores, cinceladores, herreros, sastres, barberos, molineros y panaderos, entre otros.

6 Sobre la fluctuante estructura social de la ciudad de Cartagena en el siglo XVI, véase Borrego (1983, pp. 343-346).

7 Según el Diccionario de Autoridades editado en el siglo XVIII (1979), ser virtuoso consistía en obrar honestamente conforme a la recta razón y a la ley cristiana. Este principio fue promovido en la obra de Erasmo titulada "Manual del Caballero Cristiano" y es mencionado reiteradamente por los remitentes colonizadores en sus cartas (Otte, 1996, p. 34). 
de mejor vida en la provincia de Popayán. Para ello, trazó algunas claves para alcanzar algún grado de prosperidad económica:

Si es diligente, en tres años valdrá su hacienda cinco mil ducados, si es como yo se lo he encarecido, que sabe leer y escribir y contar, y diligente en el trato de la mercadería. Porque el que por acá no entiende en estas cosas, no gana de comer, y así hay mucha gente perdida, porque el que no tiene en principio de alguna moneda, nunca tiene un real ni lo alcanzará. (Otte, 1996, p. 354)

Así entonces, sea cual fuera la actividad a desarrollar, la principal preocupación para los españoles colonizadores era cómo sobrevivir económicamente y qué tipo de negocios podían instalar en las prístinas tierras. Según Alonso de Valdemoro, residente en Cartagena, por lo menos se ganaba para comer pues, cada día que se dedicaba a trabajar, podía devengar entre doce y veinte reales y su propósito era montar una tienda en las afueras de la ciudad con lo cual aspiraba obtener de cuatro a cinco ducados de usufructo.

Eventualmente, hubo necesidad de traer de España algunos elementos o activos con los cuales emprender un proyecto productivo o conseguir rendimientos económicos a través de su comercialización.

Alonso de Zamora, asentado en 1577 en la ciudad de Santa Fe, le solicitó a su esposa, quien estaba lista para embarcarse a América, que se asegurara de traer 50 botijas de vino que podía comprarlas en Sevilla en 60 ducados mientras que en el Nuevo Reino podía negociarlas con óptimas ganancias, pues su costo ascendía a mil pesos.

Desde la población de Cáceres en la provincia de Antioquia, el capitán Alonso Rodríguez de Villaenizar pidió a sus parientes que le vendieran todos sus bienes en España y con ello trajeran un "trato" de puercos que serían destinados a alimentar a sus 40 piezas de esclavos dedicadas a la explotación minera.

Uno de los pedidos más encarecidos que realizaron los colonizadores españoles a sus amigos y parientes residentes en España era el envío de herramientas difíciles de conseguir en el Nuevo Mundo, pero que eran muy importantes para el despegue económico.

Jusepe Díaz se comunicó con su hermano residente en Jerez de la Frontera para que su mujer viniera al Nuevo Mundo, pero no sin antes vender todas sus propiedades, excepto unas herramientas que le podían resultar muy útiles en este lado del Atlántico, donde realizaba funciones como herrero.

Juan de Córdoba le pidió a su mujer que al viajar a Cartagena no olvidara de traer tijeras, puntillas de acero y patrones de cinceladores para "picar". Pedro Sánchez trabajaba en 1583 en la construcción de dos iglesias en la ciudad de Popayán, una de ellas era la catedral. Él y estaba pendiente de encargar a un viajero, que estaba pronto a embarcarse en la flota, para que le consiguiera dos clavazones para la puerta de estas edificaciones.

La llegada de los negros esclavos sucedió casi a la par de la entrada de los primeros exploradores blancos. Los primeros en arribar al Nuevo Reino fueron vinculados en el servicio doméstico o servicio personal, pero principalmente se destinaron a las labores agrícolas y a las explotaciones auríferas que ya eran un atractivo económico durante los albores de la colonización española (Ocampo, 1987, p. 38). 
El ya mencionado colono Juan de Córdoba le dio instrucciones a su esposa Catalina Pérez para que vendiera la casa que tenían en Madrid y con ese dinero comprara un negro y una negra moza, pues en España costaban 50 ducados y había, además, que sufragar dieciséis pesos de licencia para el viaje, mientras que acá su precio en el mercado esclavista llegaba a los 354 pesos de a diez reales. El negro debía ser joven para ocuparlo activamente en las labores productivas. A su llegada a Cartagena, Sebastián de Llerena invirtió el capital que traía en la compra de una cuadrilla de negros esclavos que concentró luego en las labores de explotación de oro en esa provincia.

Cuando se tenía experiencia y habilidad en algún trabajo reconocido, podía resultar más fácil alcanzar el impulso económico. Con frecuencia, los españoles radicados en América animaban a sus parientes y amigos a que ejercieran aquí sus oficios y profesiones con el aliciente de que podían contar con favorables expectativas.

Juan Sedeño recomendó a su amigo, el cerrajero Diego López, que no dudara en abandonar España para sondear nuevas oportunidades en la ciudad de Cartagena, pues con su oficio podía captar bastante dinero.

Con especial insistencia, Francisco Sánchez le escribía a su hermano Pedro para que viniera al Nuevo Continente pues, si su intención era ejercer como clérigo, en estas tierras "en pocos años será rico" (Otte, 1996, p. 356). Alonso Zamora intentó en 1577 animar al fraile Bartolomé Ortega con el acicate de que en la ciudad de Santa Fe gozaría de sobradas rentas, aproximadamente 500 ducados al año.

Miguel Hidalgo le recordó a su suegro que su profesión de médico despertaba en el Nuevo Mundo mucha admiración y obtendría crecidos estipendios. Incluso le vaticinó que en su viaje transatlántico podía ganar hasta 10.000 pesos ofreciendo sus servicios en la flota. La idea era que se radicara en el puerto de Cartagena en donde hacía tres meses no había galeno disponible, sino únicamente tres cirujanos o boticarios que ganaban "millares". En 1601 el cirujano Sebastián Jiménez recibió en España una carta de su hermano Gonzalo, radicado en la ciudad de Cali, en la que lo animaba a venir a estos parajes tropicales pues con su profesión de cirujano y su experticia en el tratamiento de cataratas podría alcanzar más dividendos de los que conseguía habitualmente en su ciudad natal, Santiago del Campo.

Es preciso aclarar que no todas las personas que los colonizadores mandaban traer resultaron tan eficientes y de buena conducta. No hay que olvidar que entre la ascendente ola de emigrantes se filtraron vagos y hombres de dudosa reputación y relajadas costumbres que se constituyeron en un problema para sus patrones y socios económicos.

Desde muy tempranas épocas, tanto la Corona como la Iglesia adoptaron medidas con el fin de erradicar a vagos y ociosos. Los vagos identificados en los primeros años de colonización en el Nuevo Reino eran por lo general españoles aventureros que se habían acostumbrado a un estilo de vida fácil. Su condición de trashumantes dificultó el accionar de las autoridades y su incorporación como fuerza laboral (Terrones, 1992).

Profundamente decepcionado se sentía en 1571 el capitán Alonso Rodríguez de Villaenizar por haber brindado alojamiento a su pariente Juan Rodríguez, quien le dilapidó un crecido capital de 14.000 reales que había logrado atesorar con sumo esfuerzo. Este hombre aprovechó la confianza que le había brindado el capitán para sacar oro en las minas de Zaragoza 
y derrochar el producto en juegos de azar, apropiándose deliberadamente de una parte de ese peculio.

Bartolomé de Moya se declaró supremamente desconcertado con la actitud de un pariente suyo que mandó traer a la provincia de Tunja, donde tenía sus negocios. Sin un peso llegó este hombre y gracias a Moya pudo levantar un buen capital que después dilapidó en apuestas de albur. Otra experiencia similar a esta le ocurrió al licenciado Briceño, quien lamentaba haber traído a la ciudad de Cali parientes "ruines" y "bellacos", especialmente un sobrino suyo. Aún en 1550 seguía endeudado por los gastos del viaje realizado por este joven desde España.

Con el fin de librarse de este tipo de inconvenientes, los colonizadores se aseguraron de tomar sus precauciones para que los emigrantes convocados fuesen individuos dispuestos al trabajo. Esta fue la advertencia que le hizo en 1582 Cristóbal de Vivas al momento de pedirle a su sobrino que viniera a América:

No traiga consigo ruin compañía, sino personas que sean de buena casta, porque acá los buenos son los que valen, y no me venga sin una información de quiénes eran sus abuelos, y si eran cristianos viejos, y más si han sido en ese pueblo y tenido cargo de justicia, y qué cargos, y aún de sus bisabuelos, y qué oficio y de qué vivían, porque hará cuenta que es ejecutoria de buena hidalguía, y esto será para mí muy gran contento. (Otte, 1996, p. 317)

Francisco González se hallaba solo en la ciudad de Santa Marta y era su anhelo que sus parientes le enviasen a alguien a quien heredarle sus cortos bienes. No obstante, aclaró que si era un hombre "travieso" y contrario a su forma de ser, como había resultado Francisco García, prefería que no se lo enviasen. El tal García había demostrado ser un holgazán, solo dedicado a "jugar y bellaquear".

\section{El contraste de experiencias exitosas y malogradas}

Fueron varios los apartes de las cartas en las que los remitentes hacían énfasis en las ventajas que brindaba América en materia económica en comparación con el complejo panorama vivido en España.

Cifras concretas sobre el tipo de trabajo, el nivel de carestía y el cálculo de los réditos sirvieron de punto de referencia para que los parientes y allegados residentes en la metrópoli pudieran convencerse de venir a aprovechar las bondades que ofrecían las tierras recién colonizadas.

A la abundancia de recursos ${ }^{8}$, exaltada desde la llegada de los primeros conquistadores, se contraponían los desalentadores reportes sobre la situación que se vivía en la península ibérica en esta segunda mitad del siglo XVI.

Los primeros españoles organizaron en el Nuevo Reino de Granada una economía centrada en la bonanza de la producción de oro y plata, todo esto complementado con la actividad

8 Sobre los usos de la abundancia de las tierras americanas, véase Saldarriaga (2012, pp. 37-44). 
agrícola, ganadera y comercial ${ }^{9}$. Este primer impulso de la economía se realizó con base en la explotación de la mano de obra indígena (Kalmanovitz, 1985, pp. 18-19).

Entre tanto, en España se había registrado en el siglo XVI un sostenido crecimiento demográfico reflejado en el incremento de la población urbana en Castilla, el rápido repoblamiento de los territorios abandonados por los musulmanes y el inicio de la colonización en América (Eiras, 1990, p. 132). Si bien se evidenció un incremento en la actividad agrícola, la ganadería y la incipiente industria, especialmente bajo el impulso de la demanda de los dominios americanos, la realidad es que ese crecimiento de la producción interna fue insuficiente y sin bases sólidas, pues no se vio reflejado en una modernización de las estructuras económicas.

Las remesas de grandes cantidades de plata y oro provenientes del Nuevo Continente generaron una fuerte inflación, pero no alcanzaron a promover el desarrollo de la economía ibérica (Caballero, 1970, p. 19) pues se destinaron más que todo a cubrir los elevados gastos de la monarquía. Particularmente, en la segunda mitad del siglo XVI, se reportaron malas cosechas, onerosos impuestos y desmedidos gastos militares, además de altas tasas de endeudamiento oficial.

Por esta época, España seguía siendo una sociedad con estamentos privilegiados, como el clero y la nobleza, cuyas prerrogativas mantenían abierta una gran brecha con los sectores populares. Muy incipiente era aún el desarrollo de la burguesía (Ballesteros, 1927, Vol. VII, pp. 153-197).

Bajo este contraste de realidades percibidas en la base del Imperio y en las colonias de ultramar, la esposa de Luis de Larraga escribía a su marido, domiciliado en Cartagena, relatándole el hambre y la mortandad que se vivía en España, haciéndole ver que lo mejor era embarcarse a América y así "le parecerá que está en [el] paraíso al respecto de lo de allá" (Otte, 1996, p. 296).

Esto fue lo que comentó desde Cartagena Alonso de Valdemoro a su hermano: "estar en esa tierra [España] es cansancio y nunca tener un real, y aquí con el favor de Dios dentro de seis años podríades ser más rico que el más rico de esa aldea, y no haríades mucho" (Otte, 1996, p. 294). Juan Sedeño señalaba desde aquel mismo puerto sobre el Caribe que, aunque la tierra era "trabajosa", de todos modos se conseguía para comer y bien podía un colono lucrar aquí para que en dos o tres años ahorrara lo suficiente para irse a la metrópoli a descansar por algún tiempo.

Antonio Portillo Cantalejo comentaba a su primo que por los lados de la ciudad de Tocaima los hombres que se dedicaban a trabajar juiciosamente ganaban en un año más de lo que podrían atesorar en España toda su vida. Martín Domínguez, por su parte, animó en 1591 a su esposa para que se trasladara a Cartagena, según él, para que gozara de los muchos "regalos" que aquí le estaba guardando. El llamado era a no temer al viaje, pues en las nuevas tierras no pasaría tantos trabajos y miserias como en España.

Bartolomé de Moya había logrado establecerse holgadamente en la ciudad de Tunja y quiso convencer a su hija para que cruzara el Atlántico en busca de un futuro promisorio. Esta

9 Por estos años Europa pasaba del feudalismo al mercantilismo y el descubrimiento del Nuevo Mundo abrió mucho más las posibilidades de dinamizar el mercado ultramarino, lo cual dio lugar a la formación de redes comerciales (Cachero, 2011, p. 29). Los primeros migrantes españoles ayudaron de algún modo a incrementar ese mercadeo a pequeña escala. 
recomendación la hizo en vista de los últimos comentarios recibidos de España, según los cuales, allí abundaban los impuestos y alcabalas, siendo tan protuberante la pobreza que la gente del común difícilmente conseguía para el diario sustento. Consideraba Moya que mejor se vivía en América, pues en su tierra natal había necesidad hasta de vender las casas para solventar necesidades básicas como el vestuario. La invitó a venir junto con su esposo, así fuera solo con sus aderezos personales, pues aquí en el Nuevo Reino no les faltaría la comida. Moya se había especializado en construir iglesias y ya había comprado cuatro esclavos que le servían como oficiales de albañilería.

Alonso Herojo, quien también se hallaba radicado en Tunja hacia el año de 1583, comentó en una misiva escrita a su esposa Teresa González que los testimonios de los españoles recién llegados daban cuenta del "espanto" que causaban las múltiples necesidades padecidas en el Viejo Continente. No en vano, cada vez aumentaba el número de peregrinos en busca de nuevas oportunidades. La experiencia demostraba que en el Nuevo Reino los aventureros no padecían miserias pues "más vale acá el mal día que el bueno en Castilla". Esto le precisó a su consorte sobre los beneficios experimentados en el nuevo suelo:

Hambres no hay acá, porque es la tierra muy abundosa de pan y de carne y de todo lo que los hombres han menester, porque el más pobre mata en su casa cada semana un carnero, y no se contenta, sino que ha de tener su gallina o pollo con su tocino asado, y si no tiene gallina, ha de tener su cuartillo de cabrito o cordero. Y pan no lo escribo porque sobra por la gracia de Dios Nuestro Señor, y de esta manera pasan acá los hombres pobres, que los ricos no los cuento, porque todo lo tienen sobrado. (Otte, 1996, p. 325)

A su yerno, Juan Hernández, Herojo lo convidó a emigrar a la provincia de Tunja con el aliciente de que bajo su respaldo no tendría que esforzarse demasiado para vivir holgado económicamente al lado de su familia, sin necesidad de alejarse de la ciudad ni de servir a nadie.

A pesar de estas percepciones favorables sobre las facilidades económicas y las posibilidades de ahorro que ofrecía el territorio novohispano, en aras de un examen más ponderado sobre la situación, algunos colonos no dudaron en reconocer que ciertos productos y servicios resultaban mucho más económicos y asequibles en España.

A través de una extensa carta formulada en 1591, esta fue la queja elevada por Baltasar Valladolid a su esposa en relación con la complicada coyuntura vivida en Santa Fe:

Es este Reino estéril y mísero. Porque hoy se hacen procesiones rogativas de agua. $Y$ vale tres pesos una fanega de trigo, que son de la moneda de allá cerca de 28 reales, y no se halla. Y tres libras de pan valen 40 maravedíes, que es tan caro como en Sevilla. Sola la vaca vale barata, y esto vale una arroba dos reales y medio, y el carnero yo le he comido más barato allá que no acá, porque aquí vale el arrelde real y medio. Y así digo que es acá más caro que no allá. Vale una vara de paño de color noventa reales, y la de negro diez ducados, y lo propio la de terciopelo, y una de tafetán y una onza de seda y una docena de botones más de veinte y dos reales, y un par de medias vale ciento y cincuenta reales. (Otte, 1996, p. 284)

Tal como se puede advertir en la mayoría de relatos, todo hace pensar que la idea era radicarse definitivamente en el Nuevo Mundo, dado lo promisorio de estas comarcas. Solo en algunos casos se habló del interés por volver a la península ibérica.

tiempo\&economía

Vol. 4 N. ${ }^{\circ} 2$ - Julio - Diciembre de 2017 
Francisco de Bolaños, asentado en un tramo del río Magdalena, dio fe de la "crueldad" que había padecido en estas tierras, pero aún así reconocía que trabajando con ahínco había logrado algún nivel de progreso. Su idea era traer a su esposa y a su hermano para acrecentar el capital y en cuatro o cinco años devolverse a España con lo cosechado y poder allí descansar con tranquilidad.

Con especial insistencia, hacia el año de 1580 Marcos Martín, residente en la ciudad de Tunja, le pidió a sus suegros y a su esposa que no dudaran en desplazarse al Nuevo Reino, pues jamás se arrepentirían de esta decisión "porque la fertilidad de esta tierra es tanta que jamás falta el comer, aunque el hombre no trabaje, y el que quiere trabajar, presto gana para poder volver a España con honra" (Otte, 1996, p. 323).

Pero si bien la mayoría de experiencias económicas de los españoles colonizadores era alentadora, no todos contaron con la misma suerte, pues hubo unos cuantos registros en los que se daba cuenta de los aprietos y fracasos que debieron afrontarse. Esto nos arroja un cuadro más complejo y realista sobre el panorama económico vivido en América.

En una carta escrita el 20 de abril de 1592 desde la ciudad de Santa Fe de Antioquia, Sebastián Gómez de Altamirano resumió muy bien las peripecias que había tenido que sobrellevar a su llegada para garantizar su subsistencia:

Para ganar de comer en las Indias es dificultoso el principio [...] que los vestidos que traje, llegado que fui a las Indias, fue necesario venderlos para remedio de mi camino, y prometo a v. m. que me he bajado para ganar un principio para ganar de comer, que no es lícito escribirlo, ni que se sepan los oficios que los hombres tienen para ganar de comer en las Indias. (Otte, 1996, p. 318)

Enfermedades inesperadas, muertes súbitas o malas inversiones pudieron menoscabar rápidamente el capital acumulado. Pero, aún por encima de estos reveses y percances, siempre había un sentimiento de resignación espiritual por considerarse que todo era voluntad divina y que prevalecía la esperanza de avizorar vientos de recuperación.

Las difíciles condiciones climáticas de esta parte de la América del Sur, especialmente las inclemencias vividas en las zonas cálidas y húmedas, pudieron quebrantar fácilmente la salud de los españoles que no estaban preparados para afrontar los embates del trópico. Estas circunstancias adversas truncaron no pocos proyectos económicos.

Uno de los que experimentaron este tipo de descalabros económicos fue Benito de Ortega, radicado en jurisdicción de la villa de Mompós en 1604. Su testimonio es muy revelador, aunque al final terminó reconociendo que, de todas maneras, mejores eran allí las perspectivas que en España.

La viuda María Bazán de Espeleta, residente en Tamalameque, había quedado muy desconsolada tras el deceso de su esposo Juan de Espeleta. Después de este incidente y de haber sido una "de las más amadas y envidiadas y prósperas mujeres de Indias", su situación económica se había visto notoriamente menguada con "tantas pérdidas y desgracias", pues se le había huido una partida de negros esclavos. La mayor parte del capital invertido por su extinto marido se había malogrado con el agravante de que en el momento acumulaba deudas que sobrepasaban los 10.000 pesos. 
Juan de Espeleta estaba ávido por volver a España, pero sus fallidos negocios en Cartagena le impidieron embarcarse en la flota. Él estaba interesado en vender poco a poco sus bienes para dejar resuelto todos sus asuntos.

\section{El casamiento como impulso económico}

Los españoles buscaron reproducir en América las costumbres de su suelo ancestral en cuanto a la institución del matrimonio. Bajo este contexto, los padres se preocuparon por casar a sus hijos con personas de noble estirpe o de crecidos capitales con tal de mantener o aumentar el prestigio social y los privilegios obtenidos. Dicho en palabras de la historiadora Guiomar Dueñas Vargas, el matrimonio era "una alianza de fortunas, de rangos sociales, de preservación de patrimonios" (1997, p. 136).

Fueron muy comunes, además, los entrecruzamientos endogámicos que patentizaban una vez más la tendencia de proteger las fortunas familiares y consolidar el poder social. La viuda María Bazán de Espeleta, radicada en 1575 en la población de Tamalameque, estaba muy empeñada en cumplir la postrera voluntad de su difundo marido de concertar la boda de su sobrina Mariquita, de tan solo ocho años de edad, con otro sobrino suyo "por emparentar con tal sangre". Para prosperidad de esta futura pareja, fue la intención del finado cónyuge dejarles algunos repartimientos de indios.

La elección de pareja era un tema de inmensas repercusiones en la sociedad de aquella época, una decisión que debía acoplarse al conjunto de valores y prejuicios reinantes. No es fortuito, entonces, que los padres asumieran un papel preponderante en esa crucial determinación, todo con miras a aumentar o revalidar los privilegios conseguidos (Rodríguez, 1997, p. 145).

Alonso Rodríguez escribió el 4 de febrero de 1578, desde la ciudad de Popayán, una carta dirigida a su padre notificándole que el día anterior se había casado sin permiso de él ni de su madre aunque a manera de consuelo reconoció que su consorte era hija de "un hombre de bien y de buenas prendas" de quien recibió como dote 20 libras de oro que equivalían a 3.000 ducados.

Algunos colonizadores españoles se preciaban de haberse comprometido en América con esposas que contaban con un buen respaldo social y económico. Juan de Camargo, residente en Tamalameque a orillas del río Magdalena, comentó a través de una carta a un familiar suyo escribano en la población de Llerena que había contraído nupcias con "una señora viuda, hermosa, principal y rica" Ilamada Catalina de Aranda de 27 años de edad, quien contaba con una fortuna estimada en 5000 pesos de oro. Esta mujer tenía una hija de nombre María, de doce años de edad, y la intención de Camargo era comprometerla maritalmente con su hijo mayor tan pronto llegara a aquella localidad ribereña.

Las favorables perspectivas económicas que se vislumbraban en América se constituyeron en un incentivo para que muchos de los parientes residentes en España tuvieran mayores oportunidades de viajar para enmaridarse con personas holgadas económicamente ${ }^{10}$. Era

10 Desde los tiempos de las primeras jornadas de Conquista, los lazos de vecindad y parentesco fueron claves para fraguar y concertar nuevas uniones maritales (Avellaneda, 1993, p. 278).

tiempo\&economía

Vol. 4 N. ${ }^{\circ} 2$ - Julio - Diciembre de 2017

p. 25 
esto, de alguna forma, una alternativa rápida y efectiva de ascenso social y de mejorar el estatus por encima de los tradicionales requisitos de nobleza y linaje que imperaban en España.

Pedro Sánchez de Corrales le recordó a Juan García Ramírez que había casado en Muzo a su hija con "un hidalgo"11 muy hombre de bien", "cristiano viejo", quien era regidor y juez depositario de bienes difuntos.

Con particular obstinación, Francisco de Bolaños instó a su mujer, Ana Mateos, residente en Moguer, para que no dudara en traer a su hija, pues sus amigos harían todo lo posible para"favorecerla" en el casamiento ya que aquí en América había mejores expectativas económicas.

Decepcionado se declaró Pedro Mantilla de los Ríos al enterarse en 1587 de que su cuñada se había enmaridado en Madrid siendo que él tenía planes previstos para casarla y para que se "acomodara" en la ciudad de Tunja "a gusto de todos con grandes riquezas" (Otte, 1996, p. 329).

Juan Muñoz quedó huérfano a muy tierna edad, pero contó con la protección constante de su primo Diego. Muñoz arribó al Nuevo Reino y alcanzó en estas tierras un gran florecimiento económico. Como una forma de resarcir aquellas atenciones recibidas desde niño, Juan le propuso a su primo que le enviara su hija y otra prima para asegurarles un buen porvenir en tierras americanas:

Yo me ofrezco casárselas en esta ciudad de Toro con dos vecinos conquistadores de esta tierra, buenos hidalgos y gente principal, porque los hay aquí, y algunos me lo han rogado. Porque, como es tierra nueva y los que la ganaron por la mayor parte solteros, casarse han, si hallasen cosa que les conviniese conforme a la calidad que en este caso que tengo intento de hacer acertaré en ello. (Otte, 1996, p. 360)

\section{Conclusiones}

Uno de los mayores aportes de las cartas privadas recopiladas por Otte y analizadas en este artículo es que amplían la visión sobre el proceso de dominación y ocupación del territorio americano, proceso que no puede percibirse exclusivamente como una empresa estatal, pues en realidad se registró una importante iniciativa privada de los vasallos españoles.

En términos reales, la Corona no contaba con la capacidad financiera para jalonar el desarrollo económico en el Nuevo Mundo y por ello promovió el proceso de colonización estableciendo algunos controles en el otorgamiento de licencias al tiempo que firmó con los conquistadores las denominadas capitulaciones, una fórmula que abría campo a la inversión privada y que le permitía a la monarquía asegurar una parte importante de las utilidades de esas labores pioneras de exploración, representadas principalmente en la producción minera.

A través del acervo epistolar se pudieron conocer en detalle los esfuerzos de sectores medios y bajos de la sociedad española (Fernández, 1983, p. 31) que buscaron bajo su propio riesgo nuevas perspectivas económicas en sus procesos migratorios al Nuevo Reino de Granada.

11 Según el Diccionario de Autoridades (1979), el hidalgo era una persona noble que venía de casa y solar conocido, con derecho a ciertos privilegios. 
Estos colonos apostaron con todas sus posibilidades al proyecto americano, destinando para ello sus ahorros y patrimonios. Fueron más que todo iniciativas individuales fortalecidas luego con la llegada de familiares y amigos ${ }^{12}$.

Las peripecias y luchas económicas que se alcanzan a detectar en los contenidos del acervo epistolario analizado en este artículo son apenas un indicio de lo complejo que resultó la dinámica de ocupación del espacio neogranadino. Queda por lo menos en evidencia que este asentamiento fue un proceso de largo aliento y afectado por múltiples interferencias internas y externas, con algunas experiencias económicas exitosas y otras no tanto. Si bien la mayoría de colonos permanecieron en América, algunos buscaron la forma de enriquecerse rápidamente y regresaron luego a España. Otros no se conformaron con los primeros caudales recogidos y siguieron su aventura en busca de nuevos tesoros.

En algunos de estos primeros colonizadores se observa una temprana diversificación en las actividades productivas, lo cual pudo eventualmente brindarles mayores posibilidades de estabilidad económica. Algunos encomenderos, por ejemplo, además de manejar los repartimientos indígenas, desplegaron otras labores alternas como el comercio a pequeña escala. Entre tanto, algunos mineros mantuvieron cultivos y cría de ganados que sirvieron de complemento para la subsistencia de sus cuadrillas de trabajadores.

Se alcanzan también a perfilar las potencialidades económicas a escala regional: la explotación aurífera en las provincias de Antioquia y Popayán, la producción de plata en la provincia de Mariquita o el énfasis en el sector agrícola y ganadero en algunas comarcas del interior del Nuevo Reino.

Fue esta segunda mitad del siglo XVI un periodo de transición con inmensos sacrificios para los colonizadores que trazaron sus proyectos de vida en América, pero sin olvidar de resolver sus negocios y asuntos familiares en la metrópoli. Se alcanzaron a percibir, además, complejas interacciones sociales y económicas no solo al interior del territorio americano, sino con España ${ }^{13}$.

Operó de esta forma un flujo de capitales de doble vía. Por un lado, la llegada de dinero, activos y mano de obra que dinamizó la incipiente economía del Nuevo Reino y, por otra parte, el envío de remesas como un paliativo a los parientes que quedaban afrontando afugias económicas en España.

En cierto modo, estos colonizadores pioneros vencieron temores y abrieron el camino para las posteriores olas masivas de emigrantes españoles ${ }^{14}$. Fueron ellos los que sentaron las bases de proyectos económicos que serían consolidados por sus descendientes y sucesores dejando como legado valiosas experiencias y alternativas de adaptación social al nuevo suelo. Fueron ellos los forjadores de las ciudades y villas que se fundaron en esa época, al ser artífices de

12 Esta situación marcó la diferencia con el proceso de colonización experimentado en las colonias inglesas, que se realizó con base en la movilización de grupos familiares (Mörner, 1969, p. 27).

13 Esta dependencia e interacción económica entre América y España se registró hasta mediados del siglo XVII cuando empezó a cimentarse una economía americana con cierto grado de autonomía (Fisher, 1992, p. 117).

14 De 2.291 vecinos españoles (padres cabeza de familia) asentados en 1570 en las provincias del Nuevo Reino de Granada, se pasó a 3.920 en el año de 1608 y dos décadas más tarde se contabilizaban ya 6.560 vecinos. (Tovar, 1994, pp. 27-28).

tiempo\&economía

Vol. 4 N. ${ }^{\circ} 2$ - Julio - Diciembre de 2017 
caminos, centros de abastecimientos y circuitos comerciales que dieron una nueva fisonomía a la economía de estos territorios.

Desde el siglo XVII la economía del Nuevo Reino sería movida más que todo con el impulso de la mayoritaria mano de obra mestiza producto de la incontenible miscegenación entre blancos e integrantes de las comunidades indígenas. Según el censo de población realizado en 1778 , se registraba un total de 203.510 blancos españoles y criollos, lo cual representaba aproximadamente una cuarta parte de la población (Tovar, 1994, pp. 86-88). No obstante, aun en las postrimerías del periodo de dominio hispánico, este segmento de la sociedad siguió manteniendo el poderío social, económico y político.

\section{Referencias}

Avellaneda Navas, J. I. (1993). La jornada de Jerónimo Lebrón al Nuevo Reino de Granada. Bogotá: Banco de la República.

Avellaneda Navas, J. I. (1995). La expedición de Gonzalo Jiménez de Quesada al mar del Sur y la creación del Nuevo Reino de Granada. Bogotá: Banco de la República.

Ballesteros y Beretta, A. (1927). La economía y la hacienda durante los Austrias. En Historia de España y su influencia en la Historia Universal (Vol. VII). Barcelona: Salvat Editorial.

Borges, A. (1972). La mujer pobladora en los orígenes americanos. En Anuario de Estudios Americanos, XXIX, 389-443.

Borrego Plá, M. C. (1983). Cartagena de Indias en el siglo XVI. Sevilla: Escuela de Estudios Hispano-americanos.

Caballero Escovar, E. (1970). Historia económica de Colombia. Bogotá: Banco de Bogotá.

Cachero Vinuesa, M. (2011). Redes mercantiles en los inicios del comercio atlántico. Sevilla entre Europa y América, 1520-1525. En N. Böttcher, y B. Hausberger (Coords.). Redes y negocios globales en el mundo ibérico, siglos XVI-XVIII (pp. 25-52). Madrid: Iberoamericana Vervuert-EI Colegio de México.

Colmenares, G. (1998). Varia. Selección de textos. Santafé de Bogotá:Tercer Mundo Editores-Universidad del Valle.

Dueñas Vargas, G. (1997). Los hijos del pecado: ilegitimidad y vida familiar en la Santafé de Bogotá colonial. Bogotá: Editorial Universidad Nacional de Colombia.

Eiras Roel, A. (1990). Evolución agraria y crecimiento demográfico en España, siglos XVI-XVII. Sémata, Ciencias Sociais e Humanidades, 3, 131-185.

Fernández Vargas, V. (1983). El control señorial en España y la emigración a las Indias. Una aproximación al tema. En F. Solano, y F. del Pino, América y la España del siglo XVI (tomo II) (pp. 27-38). Madrid: Consejo Superior de Investigaciones Científicas.

Fisher, J. R. (1992). Relaciones económicas entre España y América hasta la Independencia. Madrid: Editorial Mapfre. 
Friede, J. (1965). Descubrimiento y Conquista del Nuevo Reino de Granada. En Historia Extensa de Colombia (Vol. II). Bogotá: Ediciones Lerner.

Gutiérrez Nieto, J. I. (1983). La idea de libertad en Castilla durante el renacimiento. En F. Solano, y F. del Pino. América y la España del siglo XVI (tomo II) (pp.11-26). Madrid: Consejo Superior de Investigaciones Científicas.

Kalmanovitz, S. (1985). Economía y Nación. Una breve historia de Colombia. Medellín: Siglo XXI Editores.

Martínez, J. L. (1992). El mundo privado de los emigrantes en Indias. México: Fondo de Cultura Económica.

Mörner, M. (1969). La mezcla de razas en la historia de América Latina, Buenos Aires: Editorial Paidós.

Ocampo, J. A. (Ed.). (1987). Historia económica de Colombia. Bogotá: Siglo XXI Editores.

Otte, E. (1996). Cartas privadas de emigrantes a Indias 1540-1616. México: Fondo de Cultura Económica.

Pérez Herrero, P. (1992). Comercio y mercados en América Latina Colonial. Madrid: Editorial Mapfre.

Pita Pico, R. (2015). Los negros esclavos en Santander: desde la época de Conquista hasta las guerras de Independencia. Bucaramanga: Ediciones Universidad Industrial de Santander.

Ramos Pérez, D. (1947). Historia de la colonización española en América. Madrid: Pegaso.

Real Academia Española. (1979). Diccionario de Autoridades. Madrid: Real Academia Española, edición facsimilar.

Rodríguez, P. (1997). Sentimientos y vida familiar en el Nuevo Reino de Granada. Santa Fe de Bogotá: Editorial Ariel.

Rodríguez Lorenzo, S. M. (2017). "El contrato de pasaje en la carrera de Indias (15611622). Historia Mexicana, 66(3), 1479-1571.

Saldarriaga, G. (2012). Alimentación e identidades en el Nuevo Reino de Granada, siglos XVI y XVII. Bogotá: Ministerio de Cultura.

Terrones, M. E. (1992). Trasgresores coloniales: malentretenidos y mendigos en la ciudad de México en el siglo XVIII. En Estudios. Filosofia-Historia-Letras. Recuperado de : http://biblioteca.itam.mx/estudios/estudio/letras30/textos4/sec_1.html

Tovar Pinzón, H. (1994). Convocatoria al poder del Número. Santa Fe de Bogotá: Archivo General de la Nación.

Vicens Vives, J. (1972). Manual de historia económica de España (9a edición). Barcelona: Editorial Vicens-Vives. 